\title{
Lipid Rafts and Fas/CD95 Signaling in Cancer Chemotherapy
}

\section{Consuelo Gajate $^{1,2}$ and Faustino Mollinedo ${ }^{1}$}

${ }^{1}$ Instituto de Biología Molecular y Celular del Cáncer, Centro de Investigación del Cáncer, Consejo Superior de Investigaciones Científicas (CSIC)-Universidad de Salamanca, Campus Miguel de Unamuno, E-37007 Salamanca, Spain

${ }^{2}$ Unidad de Investigación, Hospital Universitario de Salamanca, Campus Miguel de Unamuno, E-37007 Salamanca, Spain

\section{Correspondence address:}

Consuelo Gajate: Instituto de Biología Molecular y Celular del Cáncer, Centro de Investigación del Cáncer, Consejo Superior de Investigaciones Científicas (CSIC)Universidad de Salamanca, Campus Miguel de Unamuno, E-37007 Salamanca, Spain Tel.: (+34) 923 294806; Fax: (+34) 923 294795; E-mail : cgajate@usal.es

Faustino Mollinedo: Instituto de Biología Molecular y Celular del Cáncer, Centro de Investigación del Cáncer, Consejo Superior de Investigaciones Científicas (CSIC)Universidad de Salamanca, Campus Miguel de Unamuno, E-37007 Salamanca, Spain Tel.: (+34) 923 294806; Fax: (+34) 923 294795; E-mail: fmollin@usal.es

Short Running Title: Lipid rafts and apoptotic Fas/CD95 signaling

Keywords: Lipid rafts, membrane microdomains, Fas/CD95, apoptotic signaling, cancer chemotherapy, alkyl-lysophospholipids, edelfosine, phospholipid ether. 


\section{Abstract}

Recent evidence has involved cholesterol- and sphingolipid-rich membrane domains, termed lipid rafts, in the triggering of apoptosis by the death receptor Fas/CD95. The antitumor alkyl-lysophospholipid analogue edelfosine was the first drug reported to induce apoptosis in cancer cells through recruitment and aggregation of Fas/CD95 death receptor in lipid raft clusters. Co-clustering of lipid rafts and Fas/CD95 receptor was independent of its cognate ligand FasL/CD95L, and could be pharmacologically modulated. The adaptor molecule Fas-associated death domain protein (FADD) and procaspase- 8 were also recruited at lipid rafts following edelfosine treatment, forming the death-inducing signaling complex (DISC), and hence these membrane microdomains act as scaffolds for Fas/CD95 death signaling. Edelfosine accumulated in lipid rafts of cancer cells, altering raft protein and lipid composition. Subsequent studies showed that an increasing number of antitumor drugs also were able to promote apoptosis through recruitment of Fas/CD95 into membrane rafts, and some of these compounds accumulated in raft membrane domains. Additional downstream apoptotic signaling molecules were also translocated into rafts following treatment of cancer cells with antitumor agents, thus facilitating protein-protein interactions and conveying apoptotic signals. On these grounds, lipid rafts have become an appealing and promising target for therapeutic intervention in cancer chemotherapy. Co-clustering of lipid rafts and Fas/CD95 signaling provides a new framework in anticancer therapy, and in the triggering of death receptor-mediated apoptosis, opening a new avenue in cancer chemotherapy. In this regard, an increasing number of patents are dealing with the above insights in apoptosis regulation in order to improve cancer treatment. 


\section{Introduction}

While investigating the mechanism of action of the antitumor phospholipid ether lipid edelfosine (1-O-octadecyl-2-O-methyl-rac-glycero-3-phosphocholine, ET-18- $\left.\mathrm{OCH}_{3}\right)$, the prototype of a heterogenous family of compounds collectively known as synthetic alkyl-lysophospholipid analogues (ALPs) [1,2], we found in 2000 that the induction of apoptosis triggered by this drug in leukemic cells was dependent on the death receptor Fas/CD95, which resulted aggregated in caps at the cell membrane [3]. Soon afterwards, we found out that edelfosine prompted translocation and co-clustering of Fas/CD95 into membrane rafts, thus leading to the first demonstration of the recruitment of Fas/CD95 in lipid rafts [4], and of the involvement of membrane rafts in Fas/CD95-mediated apoptosis and cancer chemotherapy [4]. Membrane rafts are membrane microdomains of reduced fluidity consisting of dynamic assemblies of cholesterol and sphingolipids $[5,6]$. The presence of saturated hydrocarbon chains in sphingolipids allows for cholesterol to be tightly intercalated, leading to the presence of distinct liquid-ordered phases, i.e. membrane rafts, dispersed in the liquid-disordered matrix, and thereby more fluid lipid bilayer. Raft disruption, following treatment with the cholesterol-depleting agent methyl- $\beta$-cyclodextrin, inhibited both edelfosine-induced Fas/CD95 clustering and apoptosis [4]. This translocation and capping of Fas/CD95 into membrane rafts following edelfosine treatment was independent of receptor interaction with its natural ligand FasL/CD95L [3, 4], indicating that Fas/CD95 aggregation and activation could be modulated pharmacologically. Subsequent studies also showed that Fas/CD95 was translocated into lipid rafts following activation with FasL/CD95L [7, 8]. On these grounds, edelfosine mimicked to some extent the action of the natural ligand FasL/CD95L on promoting death receptor clustering and capping in lipid rafts. Activation of Fas/CD95 leads to the recruitment of the adaptor molecule Fas-associated 
death domain protein (FADD) and the zymogen procaspase-8, forming the so-called “death-inducing signaling complex" (DISC) [9], containing Fas/CD95, FADD and procaspase-8. Fas/CD95 aggregation and DISC formation leads to procaspase-8 transactivation that releases mature caspase-8, thus initiating apoptosis through a subsequent caspase activation cascade $[10,11]$ or through cleavage of $\mathrm{BH} 3$-interacting domain death agonist (Bid) into truncated-Bid (t-Bid) $[12,13]$, which then triggers the mitochondrial signaling death pathway. The interaction of the Fas/CD95 death domain (DD) with the DD of the adaptor protein FADD is a critical step in assembling the DISC. Recent structural and biophysical approaches have revealed a core stoichiometry of a 5Fas/CD95:5FADD complex [14-16]. The concentration of these apoptotic molecules in rafts would favor formation of the above 5Fas/CD95:5FADD complex. The importance of lipid rafts in Fas/CD95-mediated apoptosis was further supported by the finding that overexpression of membrane sphingomyelin, a major component of lipid rafts, by transfection with sphingomyelin synthase 1 (SMS1), a gene responsible for sphingomyelin synthesis, enhanced Fas/CD95-mediated apoptosis through increasing DISC formation, activation of caspases, efficient translocation of Fas/CD95 into lipid rafts, and subsequent Fas clustering [17].

On these grounds, we hypothesize that accumulation of Fas/CD95 into aggregates of stabilized membrane lipid domains from a highly dispersed distribution may represent a general mode of regulating Fas/CD95 activation. The preset review discuss new developments and patents that set a new framework in both apoptosis regulation and tumor therapy, opening a new avenue for innovation and patenting with implications in the clinics of cancer. 


\section{Lipid rafts as Platforms for Fas/CD95 Signaling}

A growing amount of evidence (see sections below) points to the notion that membrane rafts can serve, in addition to generate a high local concentration of Fas/CD95, as platforms for coupling adaptor and effector proteins required for Fas/CD95 signaling. This is of particular significance in Fas/CD95-mediated signal transduction, as the initial signaling events depend on protein-protein interactions. Furthermore, this could facilitate and amplify signaling processes by local assembly of various cross-interacting signaling molecules. This mechanism of death receptor concentration in lipid rafts would not be only relevant to the mechanism of action of anticancer drugs, but we hypothesize this is a normal physiological process involved in apoptosis regulation, and some antitumor drugs, such as edelfosine, exacerbate this process. In this regard, clustering of Fas/CD95 in lipid rafts has been reported during spontaneous apoptosis of neutrophils [18].

The lipid molecule ceramide has been involved in the clustering of Fas/CD95 into ceramide-rich rafts [19]. However, ceramide acts as a mediator of the clustering process, not as an initiator of the process, amplifying the primary Fas/CD95 signaling events. Thus, $\mathrm{C}_{16}$-ceramide was unable to trigger Fas/CD95 clustering in the absence of stimulatory antiFas/CD95 antibody or FasL/CD95L [19]. It was suggested that Fas/CD95-FasL/CD95L complexes entered initially into small membrane rafts and induced a weak formation of the DISC, leading to caspase 8 activation [19]. This rather weak caspase 8 activation would generate ceramide through sphingomyelinase translocation to the small lipid rafts and subsequent activation. Due to the high amount of sphingomyelin present in rafts (about $70 \%$ of all cellular sphingomyelin) [20], the generated ceramide could induce coalescence of elementary rafts [19], leading to the formation of large patches containing Fas/CD95FasL/CD95L complexes that would further lead to enhanced DISC formation, thereby 
potentiating Fas/CD95 signaling. Thus, sphingomyelinase and ceramide serve to amplify the signaling of Fas/CD95 at the membrane level after the initial Fas/CD95-FasL/CD95L interaction.

Interestingly, it has been postulated that cholesterol-enriched rafts are transformed to ceramide-enriched rafts, which coalesce to larger rafts facilitating recruitment of Fas/CD95 death receptors and their connection with actin cytoskeleton via ezrin, followed by subsequent internalization and caspase activation [21, 22]. Post-translational modification of Fas/CD95 by palmitoylation at the membrane proximal cysteine residue in the cytoplasmic region (C199) is the targeting signal for Fas/CD95 localization to lipid rafts [23], whereas Y291 is important for Fas/CD95 internalization [24].

\section{Recruitment of Fas/CD95-Mediated Signaling in Lipid Rafts by Cancer Chemotherapeutic Agents}

In addition to Fas/CD95, the other two major components of DISC, namely FADD and procaspase- 8 , have been shown to be recruited into lipid rafts forming the apoptosis inducing complex upon incubation of tumor cells with a number of distinct antitumor drugs, including edelfosine [25-27], perifosine [26], cis-platin [28], resveratrol [29, 30], aplidin [31], rituximab [32], and avicin D [33]. Furthermore, additional downstream apoptotic signaling molecules, including procaspase-10, c-Jun N-terminal kinase (JNK), and Bid were also translocated into membrane rafts following cancer chemotherapy [25, 26, 30, 31, 34]. As stated above, Bid has been shown to act as a bridge between Fas/CD95 signaling and the mitochondrial-dependent pathway of apoptosis [12, 13], and persistent JNK activation has been associated with apoptosis [35, 36]. The recruitment of JNK and Bid in membrane rafts following treatment of human leukemic cells with edelfosine [25] and aplidin [31] may explain the dependence of edelfosine- 
and aplidin-mediated apoptosis on both JNK and mitochondrial signaling [36, 37]. Moreover, a link between the two major apoptotic signaling pathways, namely the death receptor-mediated extrinsic and the mitochondrial-mediated intrinsic routes following edelfosine treatment has been recently reported $[26,34]$.

Aggregation of death receptors in a rather small area of the cell, such as lipid raft membrane domains, following antitumor chemotherapy, would allow a potent synergy with death receptor ligands to achieve cell death. In this regard, a number of antitumor drugs, including resveratrol [30, 38], aplidin [31], edelfosine [26] and perifosine [26] have been reported to recruit death receptors Fas/CD95, tumor necrosis factor receptor 1 (TNFR1), and TNF-related apoptosis-inducing ligand (TRAIL) receptors death receptor (DR) 4 and DR5 into lipid rafts, and this protein redistribution sensitized the cells to death receptor stimulation by their cognate ligands or agonistic cytotoxic antibodies $[26,38]$. The above DISC apoptotic complex can also be formed with the death receptors DR4 and DR5 [39-41], and these TRAIL receptor-mediated DISCs are also suggested to be recruited into rafts following treatment with a number of antitumor drugs $[26,30,38]$. The above redistribution of death receptors and downstream signaling molecules into lipid rafts did not require protein synthesis, and therefore it was achieved from the preexisting protein pool [25].

The remarkable recruitment of death receptors, together with downstream apoptotic signaling molecules, in aggregated rafts has led us to coin the word CASMER as an acronym of "cluster of apoptotic signaling molecule-enriched rafts" [31, 34, 42, 43]. The acronym CASMER refers to the recruitment of death receptors together with downstream apoptotic signaling molecules in aggregated rafts [42, 43]. The efficiency in promoting CASMER formation, as well as CASMER protein composition, may vary depending on the cell phenotype and the triggering stimulus $[42,43]$. The basic protein 
composition of CASMER includes the recruitment of death receptors in aggregated rafts $[42,43]$. This primary CASMER requires the structure of DISC to be functionally active in apoptosis, thus leading to a second stage of CASMER complexity [42, 43]. Recent ultrastructural, genetic and pharmacologic approaches have shown the formation of DISC in aggregated rafts, that is forming a CASMER, and its role in apoptosis triggering and cancer chemotherapy $[26,27]$. A third stage of complexity in CASMER composition involves further downstream signaling molecules, such as Bid, JNK and others [42-44]. Thus, CASMER represents a novel raft-based supramolecular entity, which seems to play a critical role in the regulation of apoptosis, acting as deathpromoting scaffolds where death receptors and downstream signaling molecules are brought together, thus facilitating protein-protein interactions and the transmission of apoptotic signals $[42,43]$. On these grounds, CASMER acts as a linchpin for launching apoptotic signals.

\section{Lipid Rafts as a Target in Cancer Therapy}

The antitumor agents edelfosine, perifosine and aplidin, which promote a potent redistribution of proteins in lipid rafts leading to apoptosis [25-27, 31, 34, 45], have been reported to accumulate into cholesterol- and sphingolipid-rich lipid rafts $[4,25,27$, 31, 46-48]. Edelfosine shows a high affinity for cholesterol and for cholesterol-enriched membranes such as rafts $[49,50]$, and alters the biophysical traits of raft microdomains in membrane model systems [50]. Thus, the antitumor drugs edelfosine, perifosine and aplidin, by targeting lipid rafts, reorganize these membrane domains, promoting their clustering and redistributing their protein content, to trigger apoptosis in a Fas/CD95dependent manner. This redistribution of lipid raft protein composition is cell-type specific. Edelfosine accumulates in lipid rafts of both human leukemic cells $[25,46]$ and 
yeasts [45]. However, whereas edelfosine induces the concentration of Fas/CD95 death receptor and downstream signaling molecules into lipid rafts in leukemic cells [25], the drug selectively displaces the essential yeast plasma membrane protein Pma1p out of lipid rafts in Saccharomyces cerevisiae, as a major mediator of edelfosine toxicity in yeasts [45]. By using a Pmalp-red fluorescent protein chimera and fluorescence microscopy, Pma1p was found to move from the plasma membrane to intracellular punctuate regions, and finally localized to the yeast vacuole [45]. This Pma1p redistribution was preceded by the movement of sterols out of the plasma membrane [45]. Because the activities of proteins and signaling processes are meaningfully altered by changes in lipid raft biophysical properties, these findings point to a novel mode of action for an anti-cancer drug, through modification of plasma membrane lipid composition resulting in the displacement of an essential protein from lipid rafts in yeasts [45]. Current evidence shows that selective reorganization of lipid rafts, leading to recruitment or displacement of critical proteins, regulates the cell fate, indicating that lipid rafts act as controllers of cell death by subcellular redistribution of proteins and lipids $[25,45,51]$.

In addition, one of the characteristic features of tumor membranes is altered concentration of gangliosides and their overexpression in tumor progression [52-55]. Interestingly, a strong affinity of edelfosine to ganglioside GM1, a major component of lipid rafts, has been recently reported [56]. On these grounds, it could be envisaged that overexpression of gangliosides in tumor cells might facilitate the preferential affinity of edelfosine for cancer cell rafts overexpressing gangliosides [57]. Taken altogether, the above data support the notion that lipid rafts can be considered as a promising target in cancer therapy. 


\section{In Vivo Involvement of Cholesterol-Rich Rafts in Cancer Chemotherapy}

Very recently, we have shown evidence in tumor xenograft animal models for a potent antitumor activity of edelfosine oral administration, and the drug accumulated preferentially and dramatically in the tumor [48, 58]. Following edelfosine oral administration in non-tumor-bearing mice, a rather wide drug distribution pattern to several tissues, including lung, spleen, intestine, liver and kidney, was observed [59]. However, when severe combined immune deficiency (SCID) mice were injected with human mantle cell lymphoma, chronic lymphocytic leukemia, or multiple myeloma xenografts, edelfosine distribution was dramatically shifted towards the tumor, indicating a rather selective tumor targeting for edelfosine $[48,58]$. No apparent damage in the distinct organs analyzed following necropsy in the above in vivo studies was detected $[48,58]$. Furthermore, edelfosine lacked toxicity in rats by using histologic, functional and biochemical parameters [60]. A decrease in tumor cell cholesterol, a major raft component, inhibited the in vivo antimyeloma action of edelfosine and reduced drug uptake by the tumor [48]. These data provided the proof-of-principle and rationale for further clinical evaluation of edelfosine and for this cholesterol-rich rafttargeted therapy to improve patient outcome in cancer [48]. These data also revealed cholesterol-rich lipid rafts as a novel and efficient therapeutic target in multiple myeloma, opening a new avenue in cancer treatment [48]. Furthermore, the small tumors isolated from edelfosine-treated mice were poorly vascularized. This might be in agreement with reports showing an antiangiogenic effect of edelfosine [61].

The finding that edelfosine binds to cholesterol-rich rafts is of particular importance as the cholesterol content in tumor cells has been shown to be higher than in normal cells [62-65]. Furthermore, cancer cells have been reported to display higher 
levels of cholesterol-rich lipid rafts than their normal counterparts [66]. The ability of edelfosine to interact with cholesterol may have interesting biomedical applications, as lipid rafts are involved in a number of distinct biological processes with important biomedical consequences [67]. Taken together, the above evidences on the high cholesterol content of tumor cells and the avidity for cholesterol of edelfosine might explain, at least in part, the efficient and selective action of edelfosine as an antitumor agent $[3,68,69]$, the critical role of cholesterol-rich rafts in edelfosine anticancer action, the preferential accumulation of edelfosine in tumor cells as well as the apparent lack of toxicity exerted by this phospholipid ether in animal models.

\section{Lipid Rafts in Cancer}

Lipid rafts are small (10-200nm) heterogenous, highly dynamic, sterol- and sphingolipid-enriched domains that compartmentalize cellular processes. One of the most important role of lipid rafts at the cell surface is their function in signal transduction. Rafts act as scaffolds or concentrating platforms, and thus they facilitate protein interaction and signal transmission. In addition, if the constituents of a specific signaling route were brought together in a lipid raft, the resulting signaling complex and/or protein-protein interactions might be protected from non-raft proteins, that otherwise could negatively affect the signaling process. This is particularly important when phosphorylation processes are critical in conveying signals, taking apart both kinases and phosphatases. In this regard, a number of receptor- and tyrosine phosphorylated-mediated signaling processes (e.g.: IgE signaling, T-cell receptor, epidermal growth factor receptor, insulin receptor), which are critical for cell survival and immune response, occur in lipid rafts [5]. 
The phosphoinositide 3-kinase (PI3K)/Akt pathway is essential for cellular physiology and cell survival [70]. The serine/threonine kinase Akt (a.k.a. protein kinase $\mathrm{B}, \mathrm{PKB})$, is a central component of survival signaling, which has a multiple-step activation process [71-73]. Upon receptor-mediated activation, PI3K generates phosphatidylinositol-3,4,5-triphosphate (PIP3) through phosphorylation of phosphatidylinositol-4,5-bisphosphate (PIP2). The pleckstrin homology (PH) domain of Akt specifically recognizes PIP3, triggering Akt recruitment from the cytosol to the plasma membrane. Once in contact with the membrane, Akt undergoes an activation process involving phosphorylation by phosphoinositide-dependent kinase 1 (PDK1) and PDK2 [72, 73]. Akt is then released from the membrane and phosphorylates both cytosolic and nuclear targets. The interaction of Akt with PIP3 is therefore required for activation of Akt, by triggering its translocation to the plasma membrane. Both Akt [74, 75] and the PDKs [76, 77] have been reported to partition into rafts. Thus, lipid rafts play a crucial role in triggering the PI3K/Akt signaling pathway, by facilitating Akt recruitment and activation upon PIP3 accumulation in the plasma membrane. In this regard, through direct monitoring and controlled alterations of rafts in living cells, lipid rafts have been demonstrated to be critically involved in the membrane recruitment and activation of Akt/PKB signaling, which plays a major role in cell physiology [78, 79]. Increasing evidence suggests that integrity of lipid rafts is essential for $\mathrm{Akt} / \mathrm{PKB}$ activation and regulation of cell death $[79,80]$.

Lipid rafts seem to play a crucial role in tumor development. Data from prostate tumor animal models have shown that raising or lowering cholesterol, a critical component of rafts $[81,82]$, led to tumor growth promotion or inhibition, respectively $[83,84]$. Lipid raft cholesterol regulates apoptotic cell death in prostate cancer cells, through epidermal growth factor receptor (EGFR)-mediated Akt and extracellular 
signal-regulated kinase (ERK) pathways [85]. Increased levels of cholesterol-rich lipid rafts in cancer cells have also been reported to correlate with apoptosis sensitivity induced by cholesterol-depleting agents [66].

Edelfosine and perifosine are members of a family of compounds collectively known as antitumor alkyl-lysophospholipid analogues (ALPs). Distinct ALPs have been reported to potently inhibit Akt activation [86, 87], and also involve Fas/CD95 signaling $[3,4,25,26,88]$. On these grounds, ALPs are able to target lipid rafts leading to both death receptor signaling activation and Akt survival signaling inhibition. Thus, it might be envisaged that, by targeting lipid rafts, ALPs may activate pro-death and inhibit prosurvival pathways simultaneously Fig. (1).

\section{Modulation of Survival and Apoptotic Signaling in Rafts by Edelfosine}

Novel data suggest that apoptosis/survival signaling balance might be modified by a redistribution and local accumulation of apoptotic molecules in lipid rafts, setting apart apoptotic (Fas/CD95, FADD, caspase-8, JNK) from survival (ERK, Akt) signaling molecules [89]. In this regard, edelfosine treatment in T-cell leukemia Jurkat cells led to a recruitment of heat shock protein 90 (Hsp90) and JNK in lipid rafts, thus preserving sustained JNK activation, and identifying JNK as a novel Hsp90 client protein when both molecules were concentrated in rafts [89]. Hsp90 is a molecular chaperone, overexpressed in many tumor cells, that keeps the correct folding and function of various client proteins that promote cancer cell growth, including HER-2/Erb2, Akt, Raf-1, Bcr-Abl, and mutated p53 [90]. However, edelfosine treatment apparently took apart Hsp90 from their normal client survival proteins, and recruited this chaperone to rafts where apoptotic molecules were concentrated [89], forming a CASMER [42, 43], hence turning this chaperone into a stabilizer of apoptotic signaling. This concentration 
of apoptotic molecules, separated from survival signaling molecules, leads to a dramatic local change in the apoptosis/survival signaling ratio in a specific subcellular structure that eventually triggers a cell death response Fig. (1). In this regard, segregation in membrane rafts of pro- from anti-apoptotic insuline-like growth factor-I receptor signaling in colon carcinoma cells by members of the tumor necrosis factor superfamily has been reported [91]. Likewise, edelfosine leads to cell death in S. cerevisiae by displacement of Pmalp, a critical yeast survival protein, from lipid rafts [45]. Thus, lipid rafts serve as a potential pharmacological target in the treatment of cancer.

\section{Patents Involving the Participation of Rafts in the Regulation of Cell Death}

A number of recent patents involve the modulation of lipid rafts by distinct pharmacological agents. In particular, some novel patents are directed to the modulation of lipid raft-mediated functions and processes by platinum and sphingolipid-derived compounds [92, 93]. Lipid rafts are associated with membrane and cellular transport, cell membrane receptor function, cellular trafficking, antigen presentation, cell differentiation and activation, cytokine modulation, membrane structure and function, and protein modulation, and therefore these membrane domains are therapeutic targets for numerous biological functions. Diseases and disorders currently known to be therapeutically targeted through lipid rafts include diabetes, cancer, cardiovascular diseases, atherosclerosis, pulmonary fibrosis, multiple sclerosis, viral and prion diseases, neuronal disorders, degenerative muscular dystrophies, and autoimmune disorders [92]. On these grounds, some patents have been reported to regulate cell death through modulation of lipid rafts in both cancer [94], by interfering with insulin growth factor-I receptor signaling, and neurodegenerative diseases [95, 96]. 
Because the displacement of certain raft proteins from lipid rafts can lead to apoptosis [45, 51, 97], a patent has reported a screening method to identify new apoptosis modulating compounds [98]. In addition, because lipid rafts are dynamic structures that are internalized during cell function, a patent describes the use of synthetic lipid rafts to deliver polynucleotides, proteins, therapeutic agents, or a combination thereof to specific membrane-bound compartments of a cell [99]. In certain aspects, the synthetic vesicles were reported to deliver cargo to cellular organelles such as mitochondria [99].

\section{New Patents Involving ALPs and Their Putative Action on Lipid Rafts}

Edelfosine was the first compound reported to promote apoptosis by ligand-independent activation of Fas/CD95 death receptors, via their recruitment in lipid rafts, and to target lipid rafts in tumor cells $[3,4,25-27,46,48,58]$. Because studies conducted to uncover the edelfosine mechanism of action have contributed most to defining the processes taking place to promote apoptosis mediated by rafts, this ether phospholipid can be considered as a paradigm in raft-mediated cancer chemotherapy that leads to cell death. Edelfosine has been shown to be incorporated in a rather selective way by tumor cells $[3,26,68,69]$. How edelfosine is taken up by tumor cells remains to be elucidated, but evidence so far indicates that drug incorporation proceeds through a raft- and proteinmediated process $[25-27,46,69]$. This selectivity, together with the apparent lack of significant toxicity in animal model studies [48, 58, 60], suggest that edelfosine is a good drug candidate for prolonged treatments. A problem in cancer treatment consists in the limited duration of the use of a therapy. The toxicity of the currently available drugs, or therapeutic approaches, permits their use only in cycles, and for a limited time. Edelfosine, due to its unique traits, could be allegedly used over a very prolonged 
period of time, because of its selectivity and lack of toxicity. Edelfosine has been shown to exhibit anti-invasive activity in glioblastoma cells [100]. Interestingly, increasing evidence suggests a role for lipid rafts in metastasis [101-106]. In this regard, ALPs have been shown to inhibit metastasis and cell invasion [107-113], and a patent showed that edelfosine treatment could be useful and feasible for long-term palliative treatment of brain tumors, leading to a tumor stabilization in a high proportion of patients that had received several previous treatments [114]. During this phase II study [114], the adverse drug reactions caused by edelfosine therapy were rather mild and had a short duration. Adverse drug reactions often appeared in the first two months of the therapy, and then disappeared entirely. However, in every case, the observed symptoms were reversible within a very short period of time [114]. No cumulative toxicity, even after several years of uninterrupted therapy, was reported [114]. Previous clinical trials with edelfosine showed that hematological or systemic side-effects, such as myelosuppression, nephro-, neuro- or hepatotoxicity, were rarely observed, even after prolonged therapy $[1,67,115]$.

We have found that multiple oral administration is required to increase oral bioavailability of edelfosine [116]. In human serum, edelfosine bound to several protein components, primarily high density lipoprotein and albumin, and this may explain why cellular uptake is slowed considerably by the presence of serum or albumin in the incubation medium [117].

Hemolysis was a major side effect of edelfosine when applied intravenously [118]. This hemolytitc activity could be prevented by patented and stable liposomebased formulations of edelfosine [67, 119]. In mixtures with certain lipids, particularly sterols, edelfosine retained its apoptotic properties, while reduced its hemolytic side effect [49]. It has also been shown that, in those binary mixtures that abolish hemolysis, 
edelfosine is slowly released from the lipid mixture to the aqueous environment [49]. The fact that the slow release of edelfosine reduces or abolishes haemolysis, while keeping almost intact its apoptotic effect, suggests that both phenomena occur through different mechanisms. The molecular geometry of the lipid molecules dictates the structure of the lipid aggregates [120]. In this regard, the bilayers arising from the combination of conical and inverted conical molecules (e.g. sterols + edelfosine) appear to be more stable than those containing cylindrical and inverted conical lipids (e.g. phosphatidylcholine + edelfosine); thus, edelfosine release is slower in the former case [49].

Edelfosine shows a high affinity for cholesterol and for cholesterol-enriched membranes such as rafts $[49,50]$, due, as stated above, to the complementarity of the molecular geometrics of sterols and edelfosine [49]. The high cholesterol content in tumor cells, together with the avidity for cholesterol of edelfosine, might contribute in part to the accumulation of edelfosine in tumor cells. Nevertheless, the uptake of edelfosine by tumor cells has been suggested to be mediated by a putative protein transporter [69], which has been identified as Lem3p in Saccharomyces cerevisiae yeast [121]. It might be envisaged that tumor cells could undergo a series of changes in lipids, including cholesterol, and proteins, including transporters, that could affect raft organization in a way that facilitates edelfosine uptake. A recent patent [122] took advantage of the selective uptake of ALPs by tumor cells, and used phospholipid ether analogues labeled with a halogen radioisotope as radiolabeled tumor-specific agents to functionally identify malignant tissues and as a therapeutic option. Additional targeting vector-phospholipid conjugates are being synthesized for both therapeutic and diagnostic goals [123]. 
The fact that edelfosine and other ALPs target and act through lipid rafts [4, 25, $27,46,47,50]$, together with the involvement of these membrane domains in a wide number of critical cellular functions, has allowed to issue a growing number of patents for ALPs for distinct biomedical applications [67]. In this regard, a recent patent has taken advantage of the role of lipid rafts in IgE receptor signaling to report a method to affect allergic diseases, including asthma, through pharmacological modulation of rafts, including the ALPs miltefosine and edelfosine [124]. Another patent claims for the antiinflammatory action of edelfosine, mainly due to shedding of the raft-located L-selectin protein $[60,125]$.

Because membrane raft microdomains play a key role in the activation of death receptors and the triggering of apoptosis, the recruitment of death receptors together with downstream apoptotic signaling molecules in rafts, leading to CASMER formation $[42,43]$, sets a new insight in cancer therapy. Because this CASMER formation triggers the apoptotic machinery, the potential for raft- or CASMER-based therapies seems very promising in the treatment of cancer. In addition, this raft-mediated process might facilitate and potentiate combination therapy [26]. In this regard, a number of patents describe the use of combination therapy with perifosine, which has been reported to act through lipid rafts [26], to improve cancer treatment [126, 127].

\section{Current \& Future Developments}

Recent in vitro and in vivo data have identified lipid rafts as a novel and effective therapeutic target in some tumors, setting a novel framework in cancer chemotherapy $[4,25-27,44,48,58]$. The antitumor ether phospholipid edelfosine was the first rafttargeted drug, accumulating in lipid rafts and triggering the demise of cancer cells. Hence edelfosine can be considered as the paradigm for this new raft-targeted 
anticancer therapeutic approach. The accumulation of edelfosine in rafts might be explained, in part, by its high affinity for cholesterol $[49,50]$, due to geometry compensation of the "cone shape" of sterols and the "inverted cone shape" of edelfosine that leads to a stable bilayer [49]. Edelfosine targets membrane rafts of malignant cells, inducing raft aggregates that act as scaffolds for the recruitment and concentration of Fas/CD95 and TRAIL receptors. Previous reports have shown that a number of tumor cells, including multiple myeloma cells, express Fas/CD95, but are rather resistant to undergo apoptosis in response to the external stimulation of Fas/CD95 by agonistic antiFas/CD95 antibodies [128]. However, edelfosine activates Fas/CD95 and induces its aggregation in rafts from within the cell independently of its ligand [25], triggering subsequently downstream extrinsic and intrinsic signaling pathways that eventually lead to apoptosis $[3,4,25-27,34,129]$. Subsequent studies have allowed to extend the raftmediated antitumor therapy, initially described with edelfosine, to an increasing number of therapeutic drugs [42-44]. Elucidation of the molecular mechanism involved in the action of raft-targeted drugs, and synthesis of new compounds that efficiently achieve a raft-mediated apoptotic response in tumor cells, are promising and novel approaches in cancer therapy. This raft-mediated cancer therapy is different from the previous and currently chemotherapy programs based on targeting DNA or cell cycle-related processes, and could circumvent drug resistance as it prompts a rather direct apoptotic response in the cancer cell.

\section{Acknowledgements}

This work was supported in part by grants from the Ministerio de Ciencia e Innovación of Spain (SAF2008-02251, and RD06/0020/1037 from Red Temática de Investigación Cooperativa en Cáncer, Instituto de Salud Carlos III, cofunded by the Fondo Europeo de Desarrollo Regional of the European Union), Fondo de Investigación Sanitaria and 
European Commission (PS09/01915), European Community's Seventh Framework Programme (FP7-HEALTH-2010/256986), and Junta de Castilla y León (GR15Experimental Therapeutics and Translational Oncology Program, and Biomedicine Projects 2009 and 2010-2011). C.G. is supported by the Ramón y Cajal Program from the Spanish Ministerio de Ciencia e Innovación.

\section{Conflict of Interest}

The authors declare no potential conflict of interest.

\section{LIST OF ABBREVIATIONS}

ALPs = Alkyl-lysophospholipid analogues

Bid $=$ BH3-interacting domain death agonist

CASMER $=$ Cluster of apoptotic signaling molecule-enriched rafts

$\mathrm{DD}=$ Death domain

DISC $=$ Death-inducing signaling complex

$\mathrm{DR}=$ Death receptor

EGFR $=$ Epidermal growth factor receptor

ERK $=$ Extracellular signal-regulated kinase

ET-18-OCH $\mathrm{OH}_{3}=1-O$-octadecyl-2-O-methyl-rac-glycero-3-phosphocholine, edelfosine

FADD $=$ Fas-associated death domain protein

FasL $=$ Fas ligand

$\mathrm{JNK}=\mathrm{c}$-Jun N-terminal kinase

PDK1 = Phosphoinositide-dependent kinase 1

$\mathrm{PH}=$ Pleckstrin homology 


\author{
PI3K = Phosphoinositide 3-kinase \\ PIP2 = Phosphatidylinositol-4,5-bisphosphate \\ PIP3 = Phosphatidylinositol-3,4,5-triphosphate \\ $\mathrm{PKB}=$ Protein kinase $\mathrm{B}$ \\ SCID $=$ Severe combined immune deficiency \\ SMS1 = Sphingomyelin synthase 1 \\ $\mathrm{t}-\mathrm{Bid}=$ Truncated Bid \\ TRAIL $=$ TNF-related apoptosis-inducing ligand
}

\title{
REFERENCES
}

[1] Gajate C, Mollinedo F. Biological activities, mechanisms of action and biomedical prospect of the antitumor ether phospholipid ET-18-OCH (edelfosine), a proapoptotic agent in tumor cells. Curr Drug Metab 2002; 3: 491525.

[2] Mollinedo F, Gajate C, Martin-Santamaria S, Gago F. ET-18-OCH 3 (edelfosine): a selective antitumour lipid targeting apoptosis through intracellular activation of Fas/CD95 death receptor. Curr Med Chem 2004; 11: 3163-84.

[3] Gajate C, Fonteriz RI, Cabaner C, Alvarez-Noves G, Alvarez-Rodriguez Y, Modolell M, et al. Intracellular triggering of Fas, independently of FasL, as a new mechanism of antitumor ether lipid-induced apoptosis. Int J Cancer 2000; 85: 674-82.

[4] Gajate C, Mollinedo F. The antitumor ether lipid ET-18-OCH $\mathrm{CH}_{3}$ induces apoptosis through translocation and capping of Fas/CD95 into membrane rafts in human leukemic cells. Blood 2001; 98: 3860-3. 
[5] Simons K, Toomre D. Lipid rafts and signal transduction. Nat Rev Mol Cell Biol 2000; 1: 31-9.

[6] Munro S. Lipid rafts: elusive or illusive? Cell 2003; 115: 377-88.

[7] Hueber AO, Bernard AM, Herincs Z, Couzinet A, He HT. An essential role for membrane rafts in the initiation of Fas/CD95-triggered cell death in mouse thymocytes. EMBO Rep 2002; 3: 190-6.

[8] Scheel-Toellner D, Wang K, Singh R, Majeed S, Raza K, Curnow SJ, et al. The death-inducing signalling complex is recruited to lipid rafts in Fas-induced apoptosis. Biochem Biophys Res Commun 2002; 297: 876-9.

[9] Kischkel FC, Hellbardt S, Behrmann I, Germer M, Pawlita M, Krammer PH et al. Cytotoxicity-dependent APO-1 (Fas/CD95)-associated proteins form a deathinducing signaling complex (DISC) with the receptor. Embo J 1995; 14: 557988.

[10] Ashkenazi A, Dixit VM. Death receptors: signaling and modulation. Science 1998; 281: 1305-8.

[11] Salvesen GS, Dixit VM. Caspase activation: the induced-proximity model. Proc Natl Acad Sci U S A 1999; 96: 10964-7.

[12] Li H, Zhu H, Xu CJ, Yuan J. Cleavage of BID by caspase 8 mediates the mitochondrial damage in the Fas pathway of apoptosis. Cell 1998; 94: 491-501.

$$
\text { Luo X, Budihardjo I, Zou H, Slaughter C, Wang X. Bid, a Bcl2 }
$$
interacting protein, mediates cytochrome c release from mitochondria in response to activation of cell surface death receptors. Cell 1998; 94: 481-90.

[14] Wang L, Yang JK, Kabaleeswaran V, Rice AJ, Cruz AC, Park AY, et al. The Fas-FADD death domain complex structure reveals the basis of DISC assembly and disease mutations. Nat Struct Mol Biol 2010; 17: 1324-9. 
PC. Solution NMR investigation of the CD95/FADD homotypic death domain complex suggests lack of engagement of the CD95 C terminus. Structure 2010; 18: $1378-90$.

[16] Hymowitz SG, Dixit VM. Unleashing cell death: the Fas-FADD complex. Nat Struct Mol Biol 2010; 17: 1289-90.

[17] Miyaji M, Jin ZX, Yamaoka S, Amakawa R, Fukuhara S, Sato SB, et al. Role of membrane sphingomyelin and ceramide in platform formation for Fasmediated apoptosis. J Exp Med 2005; 202: 249-59.

[18] Scheel-Toellner D, Wang K, Assi LK, Webb PR, Craddock RM, Salmon M et al. Clustering of death receptors in lipid rafts initiates neutrophil spontaneous apoptosis. Biochem Soc Trans 2004; 32: 679-81.

[19] Grassme H, Cremesti A, Kolesnick R, Gulbins E. Ceramide-mediated clustering is required for CD95-DISC formation. Oncogene 2003; 22: 5457-70.

[20] Prinetti A, Chigorno V, Prioni S, Loberto N, Marano N, Tettamanti G, et al. Changes in the lipid turnover, composition, and organization, as sphingolipid-enriched membrane domains, in rat cerebellar granule cells developing in vitro. J Biol Chem 2001; 276: 21136-45.

[21] Patra SK. Dissecting lipid raft facilitated cell signaling pathways in cancer. Biochim Biophys Acta 2008; 1785: 182-206.

[22] Patra SK, Rizzi F, Silva A, Rugina DO, Bettuzzi S. Molecular targets of (-)-epigallocatechin-3-gallate (EGCG): specificity and interaction with membrane lipid rafts. J Physiol Pharmacol 2008; 59 Suppl 9: 217-35. 

et al. Palmitoylation is required for efficient Fas cell death signaling. Embo $\mathrm{J}$ 2007; 26: 209-20.

[24] Lee KH, Feig C, Tchikov V, Schickel R, Hallas C, Schutze S, et al. The role of receptor internalization in CD95 signaling. Embo J 2006; 25: 1009-23.

[25] Gajate C, Del Canto-Janez E, Acuna AU, Amat-Guerri F, Geijo E, Santos-Beneit AM, et al. Intracellular triggering of Fas aggregation and recruitment of apoptotic molecules into Fas-enriched rafts in selective tumor cell apoptosis. J Exp Med 2004; 200: 353-65.

[26] Gajate C, Mollinedo F. Edelfosine and perifosine induce selective apoptosis in multiple myeloma by recruitment of death receptors and downstream signaling molecules into lipid rafts. Blood 2007; 109: 711-9.

$$
\text { Gajate C, Gonzalez-Camacho F, Mollinedo F. Involvement of raft }
$$
aggregates enriched in Fas/CD95 death-inducing signaling complex in the antileukemic action of edelfosine in Jurkat cells. PLoS ONE 2009; 4: e5044.

[28] Lacour S, Hammann A, Grazide S, Lagadic-Gossmann D, Athias A, Sergent O, et al. Cisplatin-induced CD95 redistribution into membrane lipid rafts of HT29 human colon cancer cells. Cancer Res 2004;64:3593-8.

[29] Delmas D, Rebe C, Lacour S, Filomenko R, Athias A, Gambert P, et al. Resveratrol-induced apoptosis is associated with Fas redistribution in the rafts and the formation of a death-inducing signaling complex in colon cancer cells. J Biol Chem 2003; 278: 41482-90.

[30] Reis-Sobreiro M, Gajate C, Mollinedo F. Involvement of mitochondria and recruitment of Fas/CD95 signaling in lipid rafts in resveratrol-mediated antimyeloma and antileukemia actions. Oncogene 2009; 28: 3221-34. 
Ligand Concentration in Lipid Rafts Forms Apoptosis-promoting Clusters in Cancer Chemotherapy. J Biol Chem 2005; 280: 11641-7.

Fas receptor clustering and involvement of the death receptor pathway in rituximab-mediated apoptosis with concomitant sensitization of lymphoma B cells to fas-induced apoptosis. J Immunol 2007;178:2287-95. triterpenoid, induces cell apoptosis by recruitment of Fas and downstream signaling molecules into lipid rafts. PLoS One 2009; 4: e8532.

Gajate C, Gonzalez-Camacho F, Mollinedo F. Lipid raft connection between extrinsic and intrinsic apoptotic pathways. Biochem Biophys Res Commun 2009; 380: 780-4. $\mathrm{N}$-terminal kinase (JNK) in apoptosis induced by ultraviolet $\mathrm{C}$ and gamma radiation. Duration of JNK activation may determine cell death and proliferation. J Biol Chem 1996; 271: 31929-36. Jun $\mathrm{NH}_{2}$-terminal kinase activation and c-Jun in the induction of apoptosis by the ether phospholipid 1-O-octadecyl-2- $O$-methyl-rac-glycero-3phosphocholine. Mol Pharmacol 1998; 53: 602-12.

[37] Gajate C, An F, Mollinedo F. Rapid and selective apoptosis in human leukemic cells induced by Aplidine through a Fas/CD95- and mitochondrialmediated mechanism. Clin Cancer Res 2003; 9: 1535-45. 
Redistribution of CD95, DR4 and DR5 in rafts accounts for the synergistic toxicity of resveratrol and death receptor ligands in colon carcinoma cells. Oncogene 2004; 23: 8979-86.

[39] Bodmer JL, Holler N, Reynard S, Vinciguerra P, Schneider P, Juo P, et al. TRAIL receptor-2 signals apoptosis through FADD and caspase-8. Nat Cell Biol 2000; 2: 241-3.

[40] Kischkel FC, Lawrence DA, Chuntharapai A, Schow P, Kim KJ, Ashkenazi A. Apo2L/TRAIL-dependent recruitment of endogenous FADD and caspase- 8 to death receptors 4 and 5. Immunity 2000; 12: 611-20.

[41] Sprick MR, Weigand MA, Rieser E, Rauch CT, Juo P, Blenis J, et al. FADD/MORT1 and caspase- 8 are recruited to TRAIL receptors 1 and 2 and are essential for apoptosis mediated by TRAIL receptor 2. Immunity 2000; 12: 599609.

[42] Mollinedo F, Gajate C. Lipid rafts, death receptors and CASMERs: new insights for cancer therapy. Future Oncol 2010; 6: 491-4.

[43] Mollinedo F, Gajate C. Lipid rafts and clusters of apoptotic signaling molecule-enriched rafts in cancer therapy. Future Oncol 2010; 6: 811-21.

[44] Mollinedo F, Gajate C. Fas/CD95 death receptor and lipid rafts: New targets for apoptosis-directed cancer therapy. Drug Resist Updat 2006; 9: $51-73$.

[45] Zaremberg V, Gajate C, Cacharro LM, Mollinedo F, McMaster CR. Cytotoxicity of an anti-cancer lysophospholipid through selective modification of lipid raft composition. J Biol Chem 2005; 280: 38047-58.

[46] van der Luit AH, Budde M, Ruurs P, Verheij M, van Blitterswijk WJ. Alkyl-lysophospholipid accumulates in lipid rafts and induces apoptosis via raft- 
dependent endocytosis and inhibition of phosphatidylcholine synthesis. J Biol Chem 2002; 277: 39541-7.

[47] van der Luit AH, Vink SR, Klarenbeek JB, Perrissoud D, Solary E, Verheij M, et al. A new class of anticancer alkylphospholipids uses lipid rafts as membrane gateways to induce apoptosis in lymphoma cells. Mol Cancer Ther 2007; 6: 2337-45.

[48] Mollinedo F, de la Iglesia-Vicente J, Gajate C, Estella-Hermoso de Mendoza A, Villa-Pulgarin JA, Campanero MA, et al. Lipid raft-targeted therapy in multiple myeloma. Oncogene 2010; 29: 3748-57.

[49] Busto JV, del Canto-Jañez E, Goñi FM, Mollinedo F, Alonso A. Combination of the anti-tumour cell ether lipid edelfosine with sterols abolishes haemolytic side effects of the drug. J Chem Biol 2008; 1: 89-94.

[50] Ausili A, Torrecillas A, Aranda FJ, Mollinedo F, Gajate C, CorbalanGarcia $\mathrm{S}$, et al. Edelfosine is incorporated into rafts and alters their organization. J Phys Chem B 2008; 112: 11643-54.

[51] Garcia A, Cayla X, Fleischer A, Guergnon J, Alvarez-Franco Canas F, Rebollo MP, et al. Rafts: a simple way to control apoptosis by subcellular redistribution. Biochimie 2003; 85: 727-31.

[52] Hakomori S. Role of gangliosides in tumor progression. Prog Brain Res 1994; 101: 241-50.

[53] Hakomori S. Tumor malignancy defined by aberrant glycosylation and sphingo(glyco)lipid metabolism. Cancer Res 1996; 56: 5309-18.
Cazet A, Groux-Degroote
S, Teylaert
B, Kwon KM, Lehoux S,

Slomianny C, et al. GD3 synthase overexpression enhances proliferation and migration of MDA-MB-231 breast cancer cells. Biol Chem 2009; 390: 601-9. 
Hatano K, Miyamoto Y, Nonomura N, Kaneda Y. Expression of gangliosides, GD1a and sialyl paragloboside, is regulated by NF-kappaBdependent transcriptional control of alpha2,3-sialyltransferase I, II and VI in human castration-resistant prostate cancer cells. Int J Cancer (In Press). sphingolipids in selectivity of antitumor ether lipid-edelfosine. Colloids Surf B Biointerfaces 2010; 81: 492-7.

[57] Hac-Wydro K, Dynarowicz-Latka P. The relationship between the concentration of ganglioside GM1 and antitumor activity of edelfosine--the Langmuir monolayer study. Colloids Surf B Biointerfaces 2010; 81: 385-8.

[58] Mollinedo F, de la Iglesia-Vicente J, Gajate C, Estella-Hermoso de Mendoza A, Villa-Pulgarin JA, de Frias M, et al. In vitro and in vivo selective antitumor activity of Edelfosine against mantle cell lymphoma and chronic lymphocytic leukemia involving lipid rafts. Clin Cancer Res 2010;16:2046-54. de Mendoza AE, Campanero MA, de la Iglesia-Vicente J, Gajate C, Mollinedo F, Blanco-Prieto MJ, Antitumor alkyl ether lipid edelfosine: tissue distribution and pharmacokinetic behavior in healthy and tumor-bearing immunosuppressed mice. Clin Cancer Res 2009; 15: 858-64.

[60] Mollinedo F, Gajate C, Morales AI, del Canto-Janez E, Justies N, Collia F, et al. Novel anti-inflammatory action of edelfosine lacking toxicity with protective effect in experimental colitis. J Pharmacol Exp Ther 2009; 329: 43949.

[61] Zerp SF, Vink SR, Ruiter GA, Koolwijk P, Peters E, van der Luit AH, et al. Alkylphospholipids inhibit capillary-like endothelial tube formation in vitro: 
antiangiogenic properties of a new class of antitumor agents. Anticancer Drugs 2008; 19: 65-75.

Cholesterol content in tumor tissues is inversely associated with high-density lipoprotein cholesterol in serum in patients with gastrointestinal cancer. Cancer 1994; 73: 253-8.

[63] Kolanjiappan K, Ramachandran CR, Manoharan S. Biochemical changes in tumor tissues of oral cancer patients. Clin Biochem 2003; 36: 61-5.

[64] Freeman MR, Solomon KR. Cholesterol and prostate cancer. J Cell Biochem 2004; 91: 54-69.

[65] Tosi MR, Tugnoli V. Cholesteryl esters in malignancy. Clin Chim Acta 2005; 359: 27-45.

[66] Li YC, Park MJ, Ye SK, Kim CW, Kim YN. Elevated levels of cholesterol-rich lipid rafts in cancer cells are correlated with apoptosis sensitivity induced by cholesterol-depleting agents. Am J Pathol 2006; 168: 1107-18.

[67] Mollinedo F. Antitumor ether lipids: proapoptotic agents with multiple therapeutic indications. Expert Opin Ther Patents 2007; 17: 385-405.

[68] Mollinedo F, Martinez-Dalmau R, Modolell M. Early and selective induction of apoptosis in human leukemic cells by the alkyl-lysophospholipid ET-18-OCH 3 . Biochem Biophys Res Commun 1993; 192: 603-9.

[69] Mollinedo F, Fernandez-Luna JL, Gajate C, Martin-Martin B, Benito A, Martinez-Dalmau R, et al. Selective induction of apoptosis in cancer cells by the ether lipid ET-18-OCH 3 (Edelfosine): molecular structure requirements, cellular uptake, and protection by Bcl-2 and Bcl-X $\mathrm{L}_{\mathrm{L}}$. Cancer Res 1997; 57: 1320-8. 
[70] Hanada M, Feng J, Hemmings BA. Structure, regulation and function of PKB/AKT--a major therapeutic target. Biochim Biophys Acta 2004; 1697: 3-16.

[71] Scheid MP, Woodgett JR. PKB/AKT: functional insights from genetic models. Nat Rev Mol Cell Biol 2001; 2: 760-8.

[72] Scheid MP, Marignani PA, Woodgett JR. Multiple phosphoinositide 3kinase-dependent steps in activation of protein kinase B. Mol Cell Biol 2002; 22: $6247-60$.

[73] Scheid MP, Woodgett JR. Unravelling the activation mechanisms of protein kinase B/Akt. FEBS Lett 2003; 546: 108-12.

[74] Zhuang L, Lin J, Lu ML, Solomon KR, Freeman MR. Cholesterol-rich lipid rafts mediate akt-regulated survival in prostate cancer cells. Cancer Res 2002; 62: 2227-31

[75] Adam RM, Mukhopadhyay NK, Kim J, Di Vizio D, Cinar B, Boucher K, et al. Cholesterol sensitivity of endogenous and myristoylated Akt. Cancer Res 2007; 67: 6238-46.

[76] Hill MM, Feng J, Hemmings BA. Identification of a plasma membrane Raft-associated PKB Ser473 kinase activity that is distinct from ILK and PDK1. Curr Biol 2002; 12: 1251-5.

[77] Lee KY, D'Acquisto F, Hayden MS, Shim JH, Ghosh S. PDK1 nucleates $\mathrm{T}$ cell receptor-induced signaling complex for NF-kappaB activation. Science 2005; 308: 114-8.

[78] Lasserre R, Guo XJ, Conchonaud F, Hamon Y, Hawchar O, Bernard $\mathrm{AM}$, et al. Raft nanodomains contribute to Akt/PKB plasma membrane recruitment and activation. Nat Chem Biol 2008; 4: 538-47. 
Gniadecki R. Inhibition of Akt signaling by exclusion from lipid rafts in normal and transformed epidermal keratinocytes. J Invest Dermatol 2010; 130: 1136-45. Vandenabeele P, Willems J. Inhibition of spontaneous neutrophil apoptosis by parabutoporin acts independently of NADPH oxidase inhibition but by lipid raftdependent stimulation of Akt. J Leukoc Biol 2009; 85: 497-507. Lee SH, Koo KH, Park JW, Kim HJ, Ye SK, Park JB, et al. HIF-1 is induced via EGFR activation and mediates resistance to anoikis-like cell death under lipid rafts/caveolae-disrupting stress. Carcinogenesis 2009;30:1997-2004. depletion induces anoikis-like apoptosis via FAK down-regulation and caveolae internalization. J Pathol 2009; 218: 337-49. targeting alters lipid raft composition and cell survival in prostate cancer cells and xenografts. J Clin Invest 2005; 115: 959-68.

[84] Solomon KR, Pelton K, Boucher K, Joo J, Tully C, Zurakowski D, et al. Ezetimibe is an inhibitor of tumor angiogenesis. Am J Pathol 2009; 174: 101726. of lipid raft microdomains regulates apoptotic cell death in prostate cancer cells through EGFR-mediated Akt and ERK signal transduction. Prostate 2007; 67: 1061-9. 

cancer alkyl-lysophospholipids inhibit the phosphatidylinositol 3-kinaseAkt/PKB survival pathway. Anticancer Drugs 2003; 14: 167-73.

Perifosine, an oral bioactive novel alkylphospholipid, inhibits Akt and induces in vitro and in vivo cytotoxicity in human multiple myeloma cells. Blood 2006; 107: 4053-62.

[88] Matzke A, Massing U, Krug HF. Killing tumour cells by alkylphosphocholines: evidence for involvement of CD95. Eur J Cell Biol 2001; 80: 1-10.

[89] Nieto-Miguel T, Gajate C, Gonzalez-Camacho F, Mollinedo F. Proapoptotic role of $\mathrm{Hsp} 90$ by its interaction with c-Jun $\mathrm{N}$-terminal kinase in lipid rafts in edelfosine-mediated antileukemic therapy. Oncogene 2008; 27: 1779-87.

[90] Whitesell L, Lindquist SL. HSP90 and the chaperoning of cancer. Nat Rev Cancer 2005; 5: 761-72.

[91] Remacle-Bonnet M, Garrouste F, Baillat G, Andre F, Marvaldi J, Pommier G. Membrane rafts segregate pro- from anti-apoptotic insulin-like growth factor-I receptor signaling in colon carcinoma cells stimulated by members of the tumor necrosis factor superfamily. Am J Pathol 2005; 167: 76173.

[92] Kay, H. Lipid raft, caveolin protein, and caveolar function modulation compounds and associated synthetic and therapeutic methods. WO2008144616 (2008). 
[93] Braxmeier, T., Friedrichson, T., Frohner, W., Jennings, G., Schlechtingen, G., Schroeder, C., Knolker, H.-J., Simons, K., Zerial, M., Kurzchalia, T. Sphingolipid-derived phamaceutical compositions. US2008090913 (2008).

[94] Sun, H., Ghosh, P., Kim, Y. Methods of treating cancer by interfering with IGF-I receptor signaling. WO2008112297 (2008)

[95] Kim, T.-W., Dipaolo, G., Kang, M.S.., Berman, D.E.., Mcintire, L.B.J. Phosphoinositide modulation for the treatment of neurodegenerative diseases. US2010035811 (2010).

[96] Khan, AA. In vitro model for neuronal death. US20080227201 (2008).

[97] Ayllon V, Fleischer A, Cayla X, Garcia A, Rebollo A. Segregation of Bad from lipid rafts is implicated in the induction of apoptosis. J Immunol 2002; 168: 3387-93.

[98] Garcia, A., Cayla, X., Rebollo, A., Ayllon, V., Fleischer, A. Methods of screening apoptosis modulating compounds, compounds identified by said methods and use of said compounds as therapeutic agents. US2007184435 (2007).

[99] Khan, S. Synthetic lipid rafts and methods of use. WO2007112107 (2007).

[100] Engebraaten O, Bjerkvig R, Berens ME. Effect of alkyl-lysophospholipid on glioblastoma cell invasion into fetal rat brain tissue in vitro. Cancer Res 1991; 51: 1713-9.

[101] Chinni SR, Sivalogan S, Dong Z, Filho JC, Deng X, Bonfil RD, et al. CXCL12/CXCR4 signaling activates Akt-1 and MMP-9 expression in prostate 
cancer cells: the role of bone microenvironment-associated CXCL12. Prostate 2006; 66: 32-48.

[102] Zhang Q, Furukawa K, Chen HH, Sakakibara T, Urano T. Metastatic potential of mouse Lewis lung cancer cells is regulated via ganglioside GM1 by modulating the matrix metalloprotease-9 localization in lipid rafts. J Biol Chem 2006; 281: 18145-55.

[103] Chinni SR, Yamamoto H, Dong Z, Sabbota A, Bonfil RD, Cher ML. CXCL12/CXCR4 transactivates HER2 in lipid rafts of prostate cancer cells and promotes growth of metastatic deposits in bone. Mol Cancer Res 2008; 6: 44657.

[104] Xu C, Zhang YH, Thangavel M, Richardson MM, Liu L, Zhou B, et al. CD82 endocytosis and cholesterol-dependent reorganization of tetraspanin webs and lipid rafts. Faseb J 2009; 23: 3273-88.

[105] Yamaguchi H, Takeo Y, Yoshida S, Kouchi Z, Nakamura Y, Fukami K. Lipid rafts and caveolin-1 are required for invadopodia formation and extracellular matrix degradation by human breast cancer cells. Cancer Res 2009; 69: 8594-602.

[106] Duhon D, Bigelow RL, Coleman DT, Steffan JJ, Yu C, Langston W, et al. The polyphenol epigallocatechin-3-gallate affects lipid rafts to block activation of the c-Met receptor in prostate cancer cells. Mol Carcinog 2010; 49: 739-49.

[107] Storme GA, Berdel WE, van Blitterswijk WJ, Bruyneel EA, De Bruyne GK, Mareel MM. Antiinvasive effect of racemic 1-O-octadecyl-2-Omethylglycero-3-phosphocholine on MO4 mouse fibrosarcoma cells in vitro. Cancer Res 1985; 45: 351-7. 
[108] van Blitterswijk WJ, Hilkmann H, Storme GA. Accumulation of an alkyl lysophospholipid in tumor cell membranes affects membrane fluidity and tumor cell invasion. Lipids 1987; 22: 820-3.

[109] Mareel M, Bracke M, Bruyneel E, Van Larebeke N, De Mets M. Invasion and metastasis control: implications for increased therapeutic index of antitumor drugs. Cancer Treat Rev 1990; 17: 335-8.

[110] Schallier DC, Bruyneel EA, Storme GA, Hilgard P, Mareel MM. Antiinvasive activity of hexadecylphosphocholine in vitro. Anticancer Res 1991; 11: $1285-92$.

[111] Schallier DC, Bruyneel EA, Storme GA, Mareel MM. Role of the host tissue in the anti-invasive activity of the alkyllysophospholipid, ET-18-OCH 3 , in vitro. Clin Exp Metastasis 1991; 9: 579-91.

[112] van Larebeke NA, Bruyneel EA, Mareel MM. An anti-invasive concentration of the alkyl-lysophospholipid ET-18- $\mathrm{OCH}_{3}$ enhances the motility of embryonal chick heart cells cultured on solid substrate. Clin Exp Metastasis 1994; 12: 255-61.

[113] Leroy A, de Bruyne GK, Oomen LC, Mareel MM. Alkylphospholipids reversibly open epithelial tight junctions. Anticancer Res 2003; 23: 27-32.

[114] Nagler, A. Edelfosin for the treatment of brain tumors. US6514519 (2003).

[115] Berdel WE, Fink U, Rastetter J. Clinical phase I pilot study of the alkyl lysophospholipid derivative ET-18-OCH 3 . Lipids 1987;22:967-9.

[116] Estella-Hermoso de Mendoza A, Campanero MA, de la Iglesia-Vicente J, Gajate C, Mollinedo F, Blanco-Prieto MJ. Antitumor alkyl ether lipid edelfosine: tissue distribution and pharmacokinetic behavior in healthy and tumor-bearing immunosuppressed mice. Clin Cancer Res 2009; 15: 858-64. 
[117] Kelley EE, Modest EJ, Burns CP. Unidirectional membrane uptake of the ether lipid antineoplastic agent edelfosine by L1210 cells. Biochem Pharmacol 1993; 45: 2435-9.

[118] Ahmad I, Filep JJ, Franklin JC, Janoff AS, Masters GR, Pattassery J, et al. Enhanced therapeutic effects of liposome-associated 1-O-octadecyl-2-Omethyl-sn-glycero-3-phosphocholine. Cancer Res 1997;57:1915-21.

[119] Mayhew, E., Janoff, A.S., Ahmad, I., Bhatia, S.K. Etherlipid-containing multiple lipid liposomes. US6180137 (2001).

[120] Israelachvili JN, Marcelja S, Horn RG. Physical principles of membrane organization. Q Rev Biophys 1980; 13: 121-200.

[121] Hanson PK, Malone L, Birchmore JL, Nichols JW. Lem3p is essential for the uptake and potency of alkylphosphocholine drugs, edelfosine and miltefosine. J Biol Chem 2003; 278: 36041-50.

[122] Weichert, J., Longino, M. Virtual colonoscopy with radiolabeled phospholipid ether analogs. US20070098633 (2007).

[123] Bussat, P., Cherkaoui, S., Fan, H., Lamy, B., Nanjappan, P., Pillai, R., Pochon, S., Song, B., Swenson, RE. Targeting vector-phospholipids conjugates. US20090131636 (2009).

[124] Braxmeier, T., Friedrichson, T., Jennings, G. Means and methods for the treatment and prevention of allergic diseases. US2009018105 (2009).

[125] Gajate, C., Camprubi, J. Use of etherlysophospholipids as antiinflammatory agents. US6583127 (2003).

[126] Birch, R., Hendersen, I.C. Co-administration of perifosine with chemotherapeutics. WO2006081452 (2006). 
[127] Scheuring, U., Bernard, I. Combination therapy comprising a diaryl urea compound and a PI3, Akt kinase or mTOR inhibitors (rapamycins) for cancer treatment. WO2006125540 (2006).

[128] Dimberg LY, Dimberg AI, Ivarsson K, Stromberg T, Osterborg A, Nilsson K, et al. Ectopic and IFN-induced expression of Fas overcomes resistance to Fas-mediated apoptosis in multiple myeloma cells. Blood 2005; 106: $1346-54$.

[129] Gajate C, Santos-Beneit AM, Macho A, Lazaro M, Hernandez-de Rojas A, Modolell M, et al. Involvement of mitochondria and caspase-3 in ET-18$\mathrm{OCH}_{3}$-induced apoptosis of human leukemic cells. Int J Cancer 2000; 86: 20818. 
Figure 1. ALP-mediated anticancer activity via rafts. This scheme depicts a plausible model for the action of Alps trough lipid rafts. ALPs interact with lipid rafts, and promote their clustering and reorganization of their protein composition. This leads to the activation of apoptotic signaling, including CASMER formation, and inhibition of survival signaling. See text for details. 


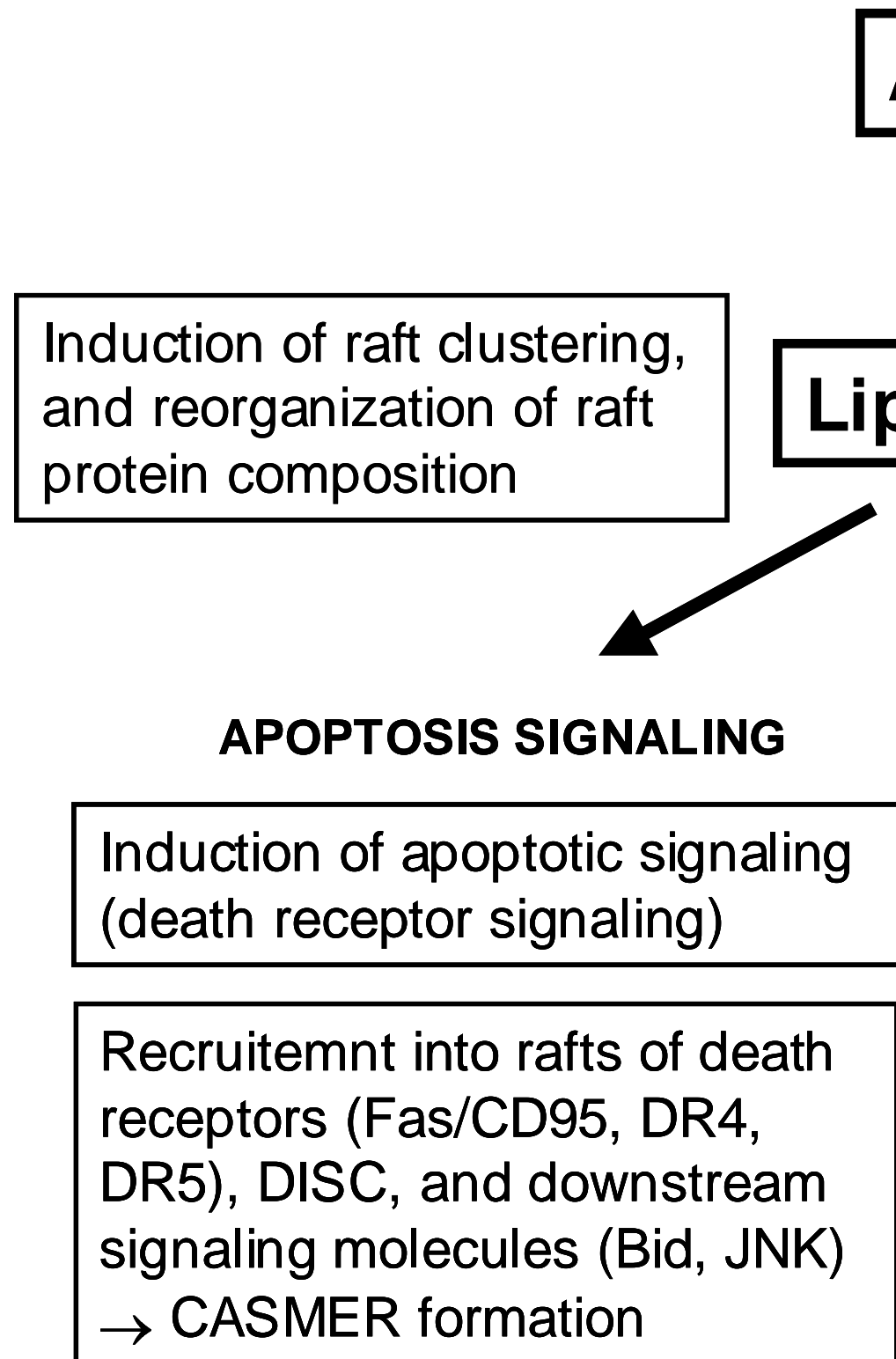

\section{ALPs}

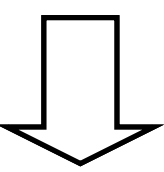

Lipid rafts

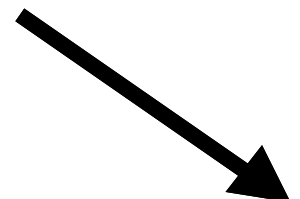

GROWTH AND SURVIVAL SIGNALING

Inhibition of survival signaling (Akt signaling)

Displacement from rafts of

Pma1p in S. cerevisiae yeasts 